\title{
Book Review: \\ Disconnected - Youth, New Media and the Ethics Gap
}

\author{
Muhterem Dindar \\ Anadolu University, Turkey
}

The diffusion of online communication tools and rise of connectivity opportunities have tremendously diminished the societal borders. These developments have led to the convergence of people and cultures from all over the world. In this regard, without considering their online environments, the physical society surrounding the individuals is not enough to get a grip on their identity and ethical values. Specifically while talking about young generations, one can even claim that their activities in the virtual territory may hold a significant proportion of their identity. In order to facilitate the moral/ethical value development of young people, a thorough investigation of their ethical dispositions in the digital world is necessary.

Hence, Carrie James's recent book Disconnected is a good reference for academics, parents and anyone looking for the ways to assist youngsters in developing their identity, moral and ethical values at the participatory, connected times. The book is published by a prestigious university publisher -The MIT Press-, which is highly committed to contemporary issues in science and technology, and tries to explore new varieties of inquiry through its publications. The books consists of 167 pages (+xxix) and shelters five chapters. The author, Carrie James, is a sociologist and Principal Investigator at Project Zero at the Harvard Graduate School of Education. She was also co-director of the Good Play Project with Howard Gardner. The book is a reflection of the data collected throughout the project. In the book, the author tries to delve deep into the minds of teenagers by putting them in a variety of ethical dilemmas. The book further goes beyond the presentation of youngsters' ethical failures, and underlines the lack of parental involvement in developing healthy digital citizens.

The book begins with a quite reader-friendly and appealing foreword which is written by the famous media scholar Henry Jenkins. Jenkins addresses how parents are desperately looking around to assure that their kids are safe when they are online. Through stating some of his genuine examples with the parents, he further points out the important gap which the current book can cover to contribute to those parents. The foreword continues with presenting opposing views on the effects of participatory culture on the net. Early optimistic views of some scholars such as Howard Rheingold and Don Tapscott are addressed. In these views, issues regarding the positive and transformative influence of the participatory culture in the web on individuals are mentioned. In addition, the way individuals are ready to act responsibly in the net are contrasted with the moral panic exposed to parents particularly through media. 
Henry Jenkins further addresses the importance of Disconnected by putting it somewhere in between these two clashing views. One of the reflections that can be derived from the foreword is the importance of creating interdisciplinary research groups. Henry Jenkins also tells the short story of the Good Play project, which brought together scholars from different backgrounds, and explains the outcomes of such collaboration. Disconnected was one of these fruitful outcomes. The foreword ends with the discussion of the challenges that individuals face while participating in the virtual communities and explains how necessary it is to develop responsible acts in the net, which is called "conscientious connectivity" in the book.

The first chapter begins with three controversial and ethical events that occurred in the digital world. Public concerns and debates around those three events are presented to the readers to push them to reflect on how ethics is and should be interwoven with the acts in the online world. The author, then provides a short description of the project and lays emphasis on the core concepts addressed throughout the book. The author proceeds with the ways youngsters think about the digital world. Then, she discusses several forms of thinking such as consequence thinking, self-focused thinking, moral thinking, ethical thinking, responsibilities thinking and community thinking. Furthermore, she draws a clear distinction between consequence, morality and ethical thinking. The ways of thinking is also discussed in terms of relevant literature on the development of ethics among the individuals.

In the following part of the chapter, Carrie James introduces blind spots and disconnectivity - unconscious and conscious insensitivity to ethical and moral behaviors. Then, she revisits those three controversial events presented at the beginning of the chapter with regard to these two core concepts. The chapter continues with the discussion of how digital media is affecting youngsters by contrasting the pessimist and the optimist views on the issue. The unique affordances of digital media is also addressed with their advantages and disadvantages to the individuals and to the society. The author concludes the chapter with the methodological grounds of their six year research project (Good Play), which led to the findings presented at the following chapters. A clear exploration of their qualitative approach is built around five themes (i.e., online identity, credibility, privacy, property, and participation), which reveals the rigorous attempts of the researchers to come up with their conclusions in the current book.

The second chapter addresses the concerns of both young people and their parents on privacy in the digital environments. At the beginning, the author describes the ethical dilemma presented to students. Several sample responses to the dilemma is then presented through direct quotations of the participants. By doing so, the author lists several approaches to online privacy which were derived from young's reasoning regarding the dilemmas. Although it might be a bit disappointing to see how majority of students fell short in abiding by the ethical behavior, their responses provide fascinating clues on their mindsets.

In the following parts of the chapter, the author goes beyond the hypothetical dilemma and presents several exemplary real life events which tell us how things we do offline might go viral in the net without our consent and control. The chapter further discusses how to deal with ethical blind spots and disconnects of students when sharing online in a highly selffocused manner. The chapter ends with the presentation of a parental perspective and involvement to youngsters going online. 
The third chapter probes into youth's perception of digital property ownership. The author begins with a Wikipedia dilemma and presents youth's dispositions on the dilemma. In addition to the property, the author addresses ethical issues regarding crediting sources and respecting copyright. The chapter continues with several real-life digital property dilemmas in terms of access and attribution, remixing, and co-creation. By doing so, the author reveals mindsets of youngsters about crediting online texts, playful online content like comics, and sharing music. She goes beyond presenting what is ethical or not according to the youngsters, and scrutinizes the main motives relying under their perspectives on the ethics of property in the net.

The later parts of the chapter provide a synthesis of sociological as well as individual factors, and the role of technology itself in digital piracy. The chapter ends through addressing the position of adults while dealing with the pervasive digital piracy among the tweens. It might be interesting for the readers to see how some adults implicitly support piracy instead of trying to prevent and diminish it.

The fourth chapter provides the audience with an in-depth understanding of the tensions that arise while young people are participating in a variety of online communities. The chapter begins with presenting a dilemma about selling worthless items to naive gamers in an online game. Then, young participants' responses to the given dilemma are discussed thoroughly.

The author continues through addressing several practices of the individuals in the participatory culture of the internet. A thorough discussion of online speech in the internet, posting in the Net, online dialogue, and online content issues -which are hot topics related to the integrity of online communities- are provided to the readers as well. Finally, the author addresses the vagueness of norms of ethics in online communities, and presents the youngsters' mindsets about the participation dilemmas. It further continues with the identified blind spots and disconnects on the issue. The parental role on the ethics and morals of participation in the net is discussed at the end of the chapter as well.

The last chapter begins with providing the audience with another cruel real-life example of an ethical failure of teens in the net. Through the incident, the author discusses that our online acts might severely harm the people around us or facilitate a positive participatory culture. The chapter continues with an overall picture of ethics gaps addressed in the previous chapters.

With the aim of narrowing down the ethical gaps, the chapter continues with the introduction of a new vision called conscientious connectivity. Ethical thinking skills, ethical sensitivity, motivation and agency, which are key elements of the conscientious connectivity, are introduced to the readers. With regard to these elements, the author ends the chapter through discussing the roles of stakeholders while developing ethical sensitivity among teenagers. The author clearly brings forth that digital content providers, educational institutions, parents, peers and individuals themselves should work in harmony to create a healthy online world.

Overall, Disconnected is a significant contribution to understand how contemporary teenagers respond to the ethical challenges they face in digital environments. One of the strengths of the book is its fluent language which extends its potential readers from 
researchers at the academy to teachers at schools and parents at the homes. It should be also noted that the ethical challenges presented through dilemmas in the book are not limited to the teenagers' digital lives. Adults come across the same issues on daily basis as well. Hence, this book would also be useful for all adults who would like to reflect on their own ethical dispositions in the online environments.

To conclude, with her book Disconnected, Carrie James filled an important gap in the literature. On the other hand, she does not go further than diagnosing the ethical mindsets of teenagers. By doing so, the author points out the need for further initiatives to provide guidance to parents and youngsters in the online worlds. When talking about ethics, it is not easy to come up with simple solutions and suggestions to deal with ever increasing complexity of the web. However, the academics and other professionals in the field should provide roadmaps to support teens when walking with the technology. It is now time to move on and create those paths to help individuals on how to find their ways, develop their identities and create meaningful interactions in the virtual contexts.

Correspondence: Muhterem Dindar, Doctoral Student, Graduate School of Educational Sciences, Anadolu University, Yunus Emre Campus, Eskisehir, Turkey 